\title{
BioMedicine
}

\section{Comparison between C4d immunohistochemical staining and other clinical- hisopathological findings in IgA nephropathy}

Follow this and additional works at: https://www.biomedicinej.com/biomedicine

Part of the Life Sciences Commons, and the Medical Sciences Commons (c) (;)

This work is licensed under a Creative Commons Attribution 4.0 License.

\section{Recommended Citation}

Kafil, Hossein Samadi and Sharifi, Hamed (2021) "Comparison between C4d immunohistochemical staining and other clinical- hisopathological findings in IgA nephropathy," BioMedicine: Vol. 11 : Iss. 2 , Article 4.

DOI: 10.37796/2211-8039.1118

This Original Articles is brought to you for free and open access by BioMedicine. It has been accepted for inclusion in BioMedicine by an authorized editor of BioMedicine. 


\title{
Comparison between C4d immunohistochemical staining and other clinical-histopathological findings in $\operatorname{IgA}$ nephropathy
}

\author{
Tala pourlak ${ }^{a}$, Seyyed Hamed Sharif Arani ${ }^{\text {b }}$, Sima Abediazar ${ }^{a}$, Hossein Samadi Kafil ${ }^{\text {c,* }}$ \\ ${ }^{a}$ Kidney Research Center, Tabriz University of Medical Sciences, Tabriz, Iran \\ ${ }^{b}$ Pharmaceutical Nanotechnology Research Center, Faculty of Medicine, Tabriz University of Medical Sciences, Tabriz, Iran \\ ${ }^{\mathrm{c}}$ Drug Applied Research Center, Tabriz University of Medical Sciences, Tabriz, Iran
}

\begin{abstract}
Introduction: IgAN occurs following abnormal $\operatorname{IgA}$ deposition in the glomerular mesangial regions. It is the most common primary glomerular disease and one of the causes of ESRD, so it is necessary to identify clinical and histopathological findings that predict progression to ESRD. In the physiopathology of this disease, $\mathrm{C}_{4} \mathrm{~d}$ causes serious renal injuries and should be counted as a significant prognostic factor too. This study examined $\mathrm{C}_{4} \mathrm{~d}$ biomarker and compare it with findings affecting prognosis, to determine the predictive value of $\mathrm{C}_{4} \mathrm{~d}$ in progression to ESRD in IgAN.

Materials and methods: In this study, all biopsy samples of IgAN patients who referred to Imam Reza Hospital in Tabriz were collected for four years. Their samples were evaluated $C_{4} d$ immunohistochemical staining and positive samples have compared with Clinical-histopathological findings affecting prognosis.

Results: In this study, $\mathrm{C}_{4} \mathrm{~d}$ positivity showed a significant association with mesangial hypercellularity $(\mathrm{p}=0.001)$, segmental glomerulosclerosis $(p=0.003)$, and endocapillary hypercellularity $(p=0.001)$; however, it did not show a significant relationship with tubular atrophy/interstitial fibrosis $(p=0.08)$. The study also found that $C_{4} d$ positivity was significantly $(p<0.05)$ correlated with hypertension, increased proteinuria, hematuria, high creatinine, and decreased mean eGFR.

Conclusion: This study showed that immunohistochemical staining of $\mathrm{C}_{4} \mathrm{~d}$ is a useful method for evaluating the prognosis of the severity of renal injuries in patients with IgAN and could be a valuable alternative for most Clinicalhistopathological factors routinely used as predictive factors for its progression to ESRD, especially when the biopsy specimen size is small and insufficient for other studies.
\end{abstract}

Keywords: $\operatorname{Ig} \mathrm{A}$ nephropathy, $\mathrm{C}_{4} \mathrm{~d}$ immunohistochemical staining

\section{Introduction}

I gA nephropathy (IgAN) is one of the most common primary glomerular diseases worldwide [1]. The disease is a type of proliferative glomerulonephritis that occurs following abnormal IgA deposition in the mesangial region of the glomeruli. In the physiopathology of this disease, the complement system, especially the subtype $\mathrm{C} 4 \mathrm{~d}$, plays an essential but unknown role by activating the lectin pathway [2]. On the other hand, it has been observed that in patients with activated lectin pathway, the risk of severe renal failure is increased and is significantly reduced within ten years [3]. Based on this evidence, it seems that $\mathrm{C} 4 \mathrm{~d}$ can be considered a significant prognostic factor as an indicator of lectin pathway activation. This disease is one of the most leading causes of end-stage renal disease (ESRD), so it is crucial to identify Clinical-histopathological factors that predict progression to ESRD. These factors include high blood pressure at the time of diagnosis [4-6], Any increase in urine protein concentrations especially values above $3.5 \mathrm{~g}$ in 24hour urine collection at the onset or persistence of symptoms [4-12], persistent isolated hematuria at

Received 22 July 2020; revised 27 February 2021; accepted 29 February 2021.

Available online 1 June 2021

* Corresponding author at: Drug Applied Research Center, Tabriz University of Medical Sciences, Tabriz 5166614711, Iran. Fax: +98 4133364661.

E-mail address: Kafilhs@tbzmed.ac.ir (H.S. Kafil). 
the time of symptoms $[7,8,13,14]$, high serum creatinine levels [7, 8, 15-18], and decreased Mean eGFR $[7-10,15,19,20]$ are among the factors that predict poor prognosis for renal survival in patients with $\operatorname{IgAN}$. There are some critical histological factors in determining the prognosis of IgA nephropathy, including mesangial hypercellularity, endocapillary hypercellularity, segmental glomerulosclerosis, and tubular atrophy/interstitial fibrosis (abbreviated MEST), which is associated with adverse renal outcomes [21]. Renal biopsy is requisite for the diagnose of IgA nephropathy [22]; however, due to the invasive nature of this procedure, as well as its importance in determining prognosis in the choice of treatment intensity at the onset of the disease $[23,24]$ and the role of C4d subtype in the induction of severe renal failure, it would be necessary to unravel the role of $\mathrm{C} 4 \mathrm{~d}$ as a critical prognostic factor, especially in cases where the biopsy specimen size is small.

\section{Materials and Methods}

In this study, all patients with renal diseases who referred to Imam Reza Hospital in Tabriz were sent to the Pathology Department of this hospital between March 2015 and September 2019. The selection of the biopsy specimen was based on IgAN confirmation by immunofluorescence (IF) studies. The inclusion criteria of biopsy specimens were 1) The severity of IgA depositions $\geq 2+[22]$ and negative $\mathrm{C} 1 \mathrm{q}$ depositions in the IF studies [25]., 2) having at least six glomeruli that fixed in formalin $10 \%$ [22] and evaluated by hematoxylin and eosin (H\&E) staining. For the analysis of the histological criteria according to the Oxford classification, nine serial sections from each specimen were providing and staining by $\mathrm{H} \& \mathrm{E}$, Jones' methenamine silver, Periodic acid-Schiff (PAS) [22]. The criteria included the presence of mesangial hypercellularity (more than $50 \%$ of glomeruli must have more than three mesangial cells as positive Specimens or cases) [22], segmental glomerulosclerosis (any amount of glomerular sclerosis as positive or cases) [22], endocapillary hyperplasia (any amount of hypercellularity in endocapillary areas as positive Specimens or cases) [22], and tubular atrophy/ interstitial fibrosis (if present it must have more than $25 \%$ of the specimen to be included as positive or cases [22], on the other hand, another histological section was prepared and mounted on a charged slide for immunohistochemical staining with a rabbit anti-C4d monoclonal IgG antibody (BioCare Medical LLC). Specimens with strong and diffused anti-C4d antibody deposition in $75 \%$ of glomeruli in the mesangial region were known as positive cases (Fig. 1) [26]. Clinical and laboratory findings including high blood pressure (blood pressure 140/ $90 \mathrm{~mm} \mathrm{Hg}$ and higher at the time of diagnosis) $[4,26]$, proteinuria (excretion of over $400 \mathrm{mg}$ of protein in 24-hour urine collection) [22]., persistent positive hematuria (with +1 dipstick strip or more during two consecutive urinalysis tests $[7,8,13,14]$, high creatinine (serum creatinine concentration above $1.4 \mathrm{mg} / \mathrm{dL}$ ) [8] and $\mathrm{eGFR}^{1}$ reduction $(60-90$ $\mathrm{ml} / \mathrm{min}$ per $1.73 \mathrm{~m}^{2}$ of body surface area as mild reduction, $30-60 \mathrm{ml} / \mathrm{min}$ per $1.73 \mathrm{~m}^{2}$ of body surface area as an average reduction, and less than $30 \mathrm{ml} /$ min per $1.73 \mathrm{~m}^{2}$ of body surface area as severe reduction) $[7-10,15,19,20]$ that collected based on physical examination and laboratory testing at the beginning of referred.

\subsection{Statistical analysis}

Demographic, clinical, and laboratory data were evaluated retrospectively. Statistical analysis was carried out using SPSS software version 21.0. Based

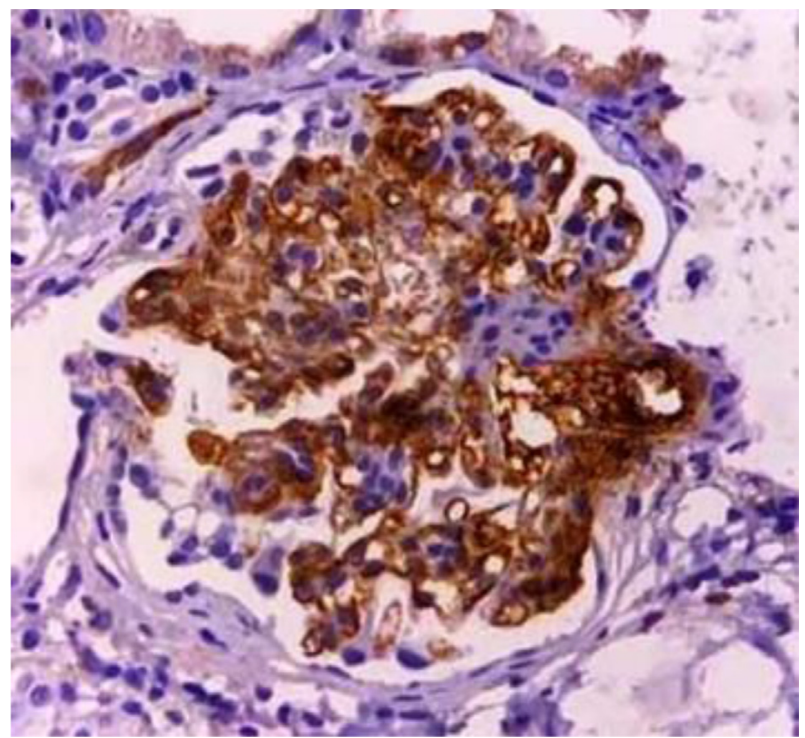

Fig. 1. Positive immunohistochemical staining of C4d. Strong immunoreactivity and diffused C4d deposition are evident in the glomerular mesangial region ( $\times 400$ magnification).

\footnotetext{
eGFR $\left(\mathrm{ml} / \mathrm{min}\right.$ per $\left.1.73 \mathrm{~m}^{2}\right)=(186 \times$ serum creatinine-1.154) $\times($ age- 0.203$) \times(0.742$ if female $) \times(1.21$ if black $)$
} 
on the qualitative and quantitative nature of the test, the results were analyzed using Pearson or Spearman tests. Finally, the data were depicted in the form of Tables and Figures.

\section{Results}

Out of a total of 51 patients with IgAN, only 48 met the required criteria to be included in our study. The age range of patients was between 15 and 63 years, and most of them were in the age range of 30 to 40 years, with a frequency of $33.3 \%$. Among patients, $66.7 \%$ were male, and $33.3 \%$ were female. Among IgAN patients, 29 patients $(60.4 \%)$ were immunohistochemically positive for $\mathrm{C} 4 \mathrm{~d}$, while 19 patients $(39.6 \%)$ were negative for this protein. In our study, there was a direct, strong, and significant correlation between the association of mesangial hypercellularity, endocapillary hypercellularity, and segmental glomerulosclerosis with C4d immunoreactivity in patients with IgAN $(P<0.05)$. It was also shown that most IgAN patients who were immunohistochemically positive for C4d were significantly more likely to have mesangial hypercellularity, endocapillary hypercellularity, and segmental glomerulosclerosis in renal histological specimens $(P<0.05)$ (Table 1$)$. In our study, although most patients with IgAN who were positive for $\mathrm{C} 4 \mathrm{~d}$ had tubular atrophy/interstitial fibrosis in renal biopsy specimens, such a correlation was not statistically significant ( $\mathrm{P}$-value $=0.081$ ) (Table 1). The statistical analysis showed that there was a significant association between decreased eGFR and increased immunoreactivity for C4d marker in patients with IgAN (P-value = 0.032 ), as the mean eGFR was $52.00 \mathrm{ml} / \mathrm{min}$ for patients who were positive for $\mathrm{C} 4 \mathrm{~d}$, while it was $68.053 \mathrm{ml} / \mathrm{min}$ for patients who were negative for this marker (Table 2). Besides, a direct, strong, and significant correlation was detected between the association of high blood pressure with $\mathrm{C} 4 \mathrm{~d}$ immunoreactivity in patients with $\operatorname{IgAN}(\mathrm{P}$-value $=$ 0.000 ) (Fig. 2). It has also been shown that most IgAN patients who were positive for $\mathrm{C} 4 \mathrm{~d}$ also had significantly higher values of $(P$-value $=0.012)$ (Table 5). Our findings demonstrated a direct, strong, and significant correlation between hematuria and $\mathrm{C} 4 \mathrm{~d}$ immunoreactivity in patients with IgAN (P-value $=0.01$ ) (Fig. 2). It was also shown that most IgAN patients who were positive for $\mathrm{C} 4 \mathrm{~d}$ in immunohistochemical evaluations were significantly more likely to have hematuria ( $\mathrm{P}$-value = 0.0005) (Table 5). Also, a direct, strong, and significant association was found between high creatinine levels and $\mathrm{C} 4 \mathrm{~d}$ immunoreactivity in patients with $\operatorname{IgAN}(\mathrm{P}$-value $=0.000)$ (Table 3$)$. It was also indicated that most IgAN patients who were positive for $\mathrm{C} 4 \mathrm{~d}$ in immunohistochemical assessments also had significantly higher concentrations of creatinine (P-value $=0.005)$ (Table 5$)$. On the other hand, the results showed that IgAN patients who were positive for $\mathrm{C} 4 \mathrm{~d}$ in immunohistochemical evaluations had a higher average creatinine level compared with patients who were negative for this marker $(2.05 \mathrm{mg} / \mathrm{dl}$ vs. $1.22 \mathrm{mg} / \mathrm{dl})$ (Table 3). The results showed a direct, strong, and significant relationship between proteinuria with $\mathrm{C} 4 \mathrm{~d}$ immunoreactivity in patients with $\operatorname{IgAN}(\mathrm{P}$-value $=0.000)$ (Table 4). It was also shown that most IgAN patients who were positive for $\mathrm{C} 4 \mathrm{~d}$ also had a significant extent of proteinuria (P-value $=0.000$ ) (Table 5). Our study indicated that IgAN patients who were positive for $\mathrm{C} 4 \mathrm{~d}$ also had a higher average protein excretion in their urine compared with C4d-negative patients $(2.24 \mathrm{~g} /$ day vs. $1.09 \mathrm{~g} /$ day) (Table 4).

\section{Discussion}

IgA nephropathy is a common kidney disease that, through IgA deposition and with various mechanisms such as $\mathrm{C} 4 \mathrm{~d}$ deposition in the kidney leads to changes in clinical and histopathologic signs for the patient, and play an important role in the future for prediction of prognosis of the disease. In this investigation, we tried to study the predictive value of $\mathrm{C} 4 \mathrm{~d}$ as a new marker in association with other criteria affecting prognosis.

Table 1. Relationship between histopathologic factors and C4d immunoreactivity.

\begin{tabular}{|c|c|c|c|c|c|}
\hline \multirow[t]{2}{*}{ Histological } & \multirow[t]{2}{*}{ Category } & \multicolumn{2}{|l|}{$\mathrm{C}_{4} \mathrm{~d}$} & \multirow[t]{2}{*}{ P-Value } & \multirow[t]{2}{*}{ Chi-Square } \\
\hline & & Positive & Negative & & \\
\hline \multirow[t]{2}{*}{ Mesangial hypercellularity } & Positive & $23(82.1 \%)$ & $5(17.9 \%)$ & \multirow[t]{2}{*}{0.000} & \multirow[t]{2}{*}{13.264} \\
\hline & Negative & $6(30 \%)$ & $14(70 \%)$ & & \\
\hline \multirow[t]{2}{*}{ Endocapillary proliferation } & Positive & $20(87 \%)$ & $3(13 \%)$ & \multirow[t]{2}{*}{0.000} & \multirow[t]{2}{*}{13.006} \\
\hline & Negative & $9(36 \%)$ & $16(64 \%)$ & & \\
\hline \multirow[t]{2}{*}{ Segmental glomerulosclerosis } & Positive & $23(79.3 \%)$ & $6(20.7 \%)$ & \multirow[t]{2}{*}{0.001} & \multirow[t]{2}{*}{10.936} \\
\hline & Negative & $6(31.6 \%)$ & $13(68.4 \%)$ & & \\
\hline \multirow[t]{2}{*}{ The proportional of tubular/atrophy and interstitial fibrosis } & Positive & $15(75 \%)$ & $5(25 \%)$ & \multirow[t]{2}{*}{0.081} & \multirow[t]{2}{*}{3.049} \\
\hline & Negative & $14(50 \%)$ & $14(50 \%)$ & & \\
\hline
\end{tabular}


Table 2. The association between eGFR and C4d immunoreactivity.

\begin{tabular}{|c|c|c|c|c|c|c|c|}
\hline & & \multicolumn{3}{|l|}{ eGFR } & \multicolumn{2}{|c|}{ Spearman Correlation } & \multirow[t]{2}{*}{ Mean \pm S D } \\
\hline & & $>60$ & $30-60$ & $30>$ & P-Value & Phi & \\
\hline $\mathrm{C} 4 \mathrm{~d}$ & Positive & $10(45.5 \%)$ & $12(66.7 \%)$ & $7(87.5 \%)$ & 0.032 & -0.311 & $52.00 \pm 25.53$ \\
\hline
\end{tabular}

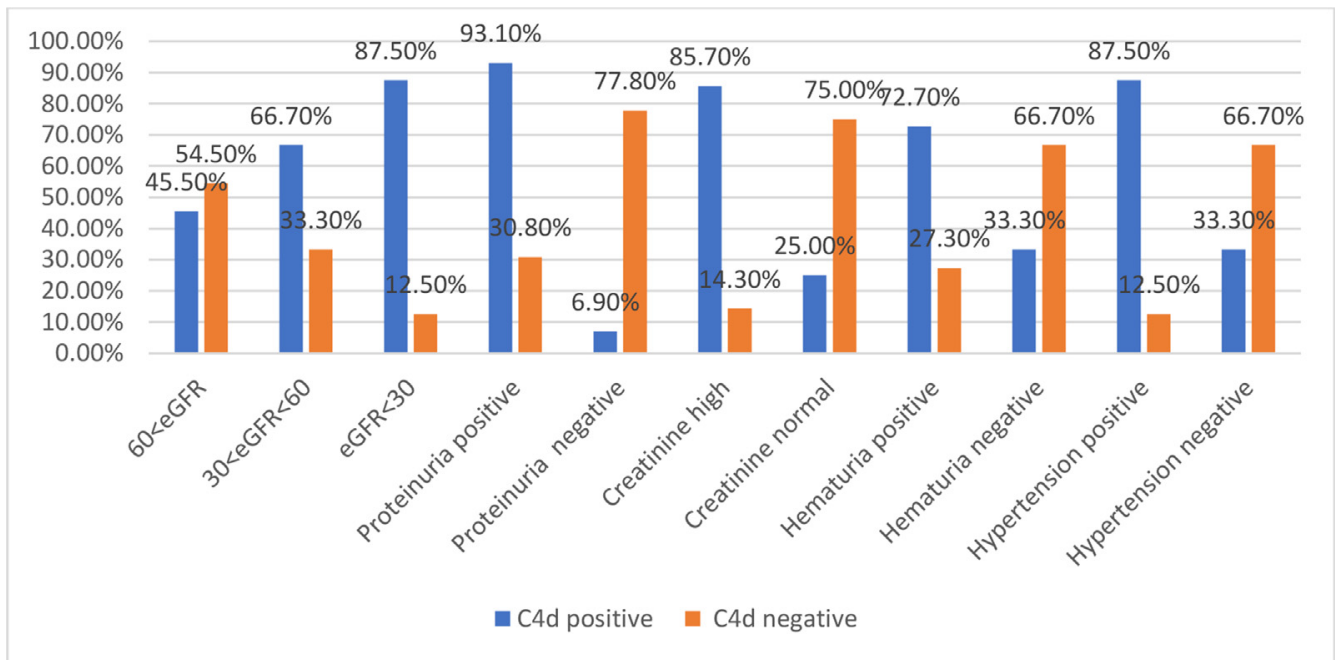

Fig. 2. Comparison of Clinical-pathology factors with C4d immunoreactivity.

Table 3. The relationship between creatinine and C4d immunoreactivity.

\begin{tabular}{|c|c|c|c|c|c|c|}
\hline & \multicolumn{2}{|l|}{ Creatinine } & \multicolumn{3}{|c|}{ Pearson Correlation } & \multirow[t]{2}{*}{ Mean \pm SD } \\
\hline & Creatinine positive & Creatinine negative & Chi-Square & P-Value & Phi & \\
\hline C4d Positive & $24(85.7 \%)$ & $5(25 \%)$ & 17.938 & 0.000 & 0.612 & $2.05 \pm 1.15$ \\
\hline C4d Negative & $4(14.3 \%)$ & $15(75 \%)$ & & & & $1.22 \pm 0.37$ \\
\hline
\end{tabular}

Table 4. The correlation between proteinuria and C4d immunoreactivity.

\begin{tabular}{|c|c|c|c|c|c|c|}
\hline & & \multicolumn{2}{|l|}{ Proteinuria } & \multicolumn{2}{|c|}{$\begin{array}{l}\text { Correlation test } \\
\text { results }\end{array}$} & \multirow[t]{2}{*}{ Mean \pm SD } \\
\hline & & Proteinuria positive & Proteinuria negative & P-Value & Phi & \\
\hline \multirow[t]{2}{*}{$\mathrm{C} 4 \mathrm{~d}$} & Positive & $27(93.1 \%)$ & $2(6.9 \%)$ & 0.000 & 0.517 & $2.24 \pm 1.32$ \\
\hline & Negative & $12(30.8 \%)$ & $7(77.8 \%)$ & & & $1.09 \pm 1.25$ \\
\hline
\end{tabular}

C4d plays a significant role in activating the lectin pathway [2], and by producing a variety of pro-inflammatory mediators, it causes mesangial hypercellularity $[27,28]$ as well as focal And or segmental glomerulosclerosis [3]. On the other hand, subendothelial C4d deposits [22], especially in the glomerular area [29], can lead to damage to podocytes through endocapillary proliferation [22]. As a result, the association between $\mathrm{C} 4 \mathrm{~d}$ and histological factors affecting prognosis in our study and other studies [26,30-32] suggests a negative effect of C4d on prognosis. However, the association between C4d positivity and tubular atrophy/interstitial fibrosis in the present research, unlike other studies
[26,30-32], could be due to the higher specificity of the monoclonal antibody used in our study. However, higher positive C4d cases in the study group without tubular atrophy/interstitial fibrosis may be because of more important than C4d deposition in glomerular damage than extra-glomerular injury [29], as well as concomitant glomerular damage with tubular atrophy and interstitial fibrosis in positive C4d cases. Glomerular C4d deposition, followed by renal failure [34], impairs glomerular filtration, and increases serum creatinine as two factors affecting prognosis. Our study, similar to other studies $[26,31,33]$, showed that C4d positivity with a decrease in mean eGFR to less than $60 \mathrm{ml} / \mathrm{min}$ 
Table 5. Relationship between Clinic-histopathologic factors in patients with positive C4d based on the binomial distribution.

\begin{tabular}{|c|c|c|c|c|}
\hline & & Frequency $\mathrm{C}_{4} \mathrm{~d}$ positive & Observed Proportion & P-Value \\
\hline \multirow[t]{2}{*}{ Mesangial hypercellularity } & Positive & 23 & $79 \%$ & 0.001 \\
\hline & Negative & 6 & $21 \%$ & \\
\hline \multirow[t]{2}{*}{ Endocapillary proliferation } & Positive & 20 & $69 \%$ & 0.003 \\
\hline & Negative & 9 & $31 \%$ & \\
\hline \multirow[t]{2}{*}{ Segmental glomerulosclerosis } & Positive & 23 & $79 \%$ & 0.001 \\
\hline & Negative & 6 & $21 \%$ & \\
\hline \multirow[t]{2}{*}{ Hypertension } & Positive & 21 & $72 \%$ & 0.012 \\
\hline & Negative & 8 & $28 \%$ & \\
\hline \multirow[t]{2}{*}{ Hematuria } & Positive & 24 & $83 \%$ & 0.0005 \\
\hline & Negative & 5 & $17 \%$ & \\
\hline \multirow[t]{2}{*}{ Creatinine } & Positive & 24 & $83 \%$ & 0.005 \\
\hline & Negative & 5 & $17 \%$ & \\
\hline \multirow[t]{2}{*}{ Proteinuria } & Positive & 27 & $93 \%$ & 0.000 \\
\hline & Negative & 2 & $7 \%$ & \\
\hline
\end{tabular}

caused significant destruction in renal function. Our study, similar to other studies, showed that C4d positivity with a decrease in mean eGFR to less than $60 \mathrm{ml} / \mathrm{min}$ caused significant destruction in renal function. On the other hand, according to our study and other previous researches [32] [26], C4d-negative patients had an average creatinine excretion of less than $1.25 \mathrm{mg} / \mathrm{dl}$, while $\mathrm{C} 4 \mathrm{~d}$-positive patients had a moderate creatinine level above $1.68 \mathrm{mg} / \mathrm{dl}$, which according to previous studies can respectively lead to ESRD by $2.5 \%$ and $71 \%$, within ten years [8]. The co-occurrence between $\mathrm{C} 4 \mathrm{~d}$ positivity and high blood pressure in our study and other investigations $[26,31,33]$ can be exhibited severity renal injury in the kidney of IgAN patients. C4d deposits in the mesangial area can probably be through the proliferation of mesangial cells, secretion of extracellular matrix components [35]. Previous studies showed C4dstaining was more correlative with the endocapillary proliferation score of the Oxford classification, than with the mesangial changes [36]. Increased expression of $\beta T G F$, and activation of the renin-angiotensin system [37-39] lead to hypertension, renal injury and finally poor prognosis in the IgAN patients. The present study confirmed the concurrence of $\mathrm{C} 4 \mathrm{~d}$ deposition and hematuria. The emergence of hematuria at the time of the beginning of disease may be correlated with a higher risk of ESRD in the future $[7,8,13,14]$. Also, the presence of RBCs inside the tubules, as a result of hematuria, causes severe injuries to the kidneys by causing acute tubular necrosis $[7,8,13,14]$. Therefore, regardless of the damage mechanism of hematuria, a positive $\mathrm{C} 4 \mathrm{~d}$ will adversely influence the patient's prognosis. Our study, similar to other studies [26,31,33], showed that $\mathrm{C} 4 \mathrm{~d}$ negativity causes average proteinuria of about 1 gram per day, whereas $\mathrm{C} 4 \mathrm{~d}$ positivity leads to an increase in proteinuria of more than 1 gram per day. Such an effect stems from C4d glomerular deposition and the resulting glomerular damage [34]. Therefore, due to the negative effect of proteinuria increase on prognosis, a positive $\mathrm{C} 4 \mathrm{~d}$ will result in a poor prognosis for the patient.

Finally, it can be inferred that C4d is a useful biomarker in assessing the prognosis of the severity of renal injury in IgAN patients and could be a worthy alternative to most clinical-histopathological factors predicting the progression towards ESRD.

\section{Conflict of interest}

None to declare.

\section{Acknowledgments}

This study was supported by Connective Tissue diseases Research Center, Tabriz University of Medical Sciences with grant number 59731. The study was approved by the local ethic committee with the number IR.TBZMED.REC.1397.313. We thank collaboration by all Imam Reza Hospital staff for their help and participation. First and second authors had equal participation in this study.

\section{References}

[1] Fogo AB, Kashgarian M. Diagnostic Atlas of Renal Pathology E-Book. Elsevier Health Sciences; 2016.

[2] Wu M-Y, Chen C-S, Yiang G-T, Cheng P-W, Chen Y-L, Chiu $\mathrm{H}-\mathrm{C}$, et al. The emerging role of pathogenesis of IgA nephropathy. Journal of clinical medicine 2018;7(8):225.

[3] Espinosa M, Ortega R, Gómez-Carrasco JM, López-Rubio F, López-Andreu M, López-Oliva MO, et al. Mesangial C4d deposition: a new prognostic factor in IgA nephropathy. Nephrology Dialysis Transplantation 2008;24(3):886-91.

[4] Berthoux F, Mohey H, Laurent B, Mariat C, Afiani A, Thibaudin L. Predicting the risk for dialysis or death in $\operatorname{IgA}$ nephropathy. Journal of the American Society of Nephrology 2011;22(4):752-61.

[5] Bartosik LP, Lajoie G, Sugar L, Cattran DC. Predicting progression in IgA nephropathy. American journal of kidney diseases 2001;38(4):728-35. 
[6] Reich HN, Troyanov S, Scholey JW, Cattran DC. Remission of proteinuria improves prognosis in IgA nephropathy. Journal of the American Society of Nephrology 2007;18(12): 3177-83.

[7] Rekola S, Bergstrand A, Bucht H. Deterioration of GFR in IgA nephropathy as measured by 51Cr-EDTA clearance. Kidney international 1991;40(6):1050-4.

[8] Wakai K, Kawamura T, Endoh M, Kojima M, Tomino Y, Tamakoshi A, et al. A scoring system to predict renal outcome in IgA nephropathy: from a nationwide prospective study. Nephrology Dialysis Transplantation 2006;21(10): 2800-8.

[9] Donadio JV, Bergstralh EJ, Grande JP, Rademcher DM. Proteinuria patterns and their association with subsequent end-stage renal disease in $\operatorname{IgA}$ nephropathy. Nephrology Dialysis Transplantation 2002;17(7):1197-203.

[10] Izzi C, Ravani P, Torres D, Prati E, Viola BF, Guerini S, et al. IgA nephropathy: the presence of familial disease does not confer an increased risk for progression. American journal of kidney diseases 2006;47(5):761-9.

[11] Le W, Liang S, Hu Y, Deng K, Bao H, Zeng C, et al. Longterm renal survival and related risk factors in patients with IgA nephropathy: results from a cohort of 1155 cases in a Chinese adult population. Nephrology Dialysis Transplantation 2011;27(4):1479-85.

[12] Maixnerova D, Bauerova L, Skibova J, Rysava R, Reiterova J, Merta M, et al. The retrospective analysis of 343 Czech patients with IgA nephropathy-one centre experience. Nephrology Dialysis Transplantation 2011;27(4):1492-8.

[13] Szeto C-C, Lai FM-M, To K-F, Wong TY-H, Chow K-M, Choi PC-L, et al. The natural history of immunoglobulin a nephropathy among patients with hematuria and minimal proteinuria. The American journal of medicine 2001;110(6): 434-7.

[14] Vivante A, Afek A, Frenkel-Nir Y, Tzur D, Farfel A, Golan E, et al. Persistent asymptomatic isolated microscopic hematuria in Israeli adolescents and young adults and risk for end-stage renal disease. Jama 2011;306(7):729-36.

[15] D'Amico G. Influence of clinical and histological features on actuarial renal survival in adult patients with idiopathic IgA nephropathy, membranous nephropathy, and membranoproliferative glomerulonephritis: survey of the recent literature. American journal of kidney diseases 1992;20(4): 315-23.

[16] Alamartine E, Sabatier J-C, Guerin C, Berliet J-M, Berthoux F. Prognostic factors in mesangial IgA glomerulonephritis: an extensive study with univariate and multivariate analyses. American journal of kidney diseases 1991;18(1):12-9.

[17] Johnston P, Brown J, Braumholtz D, Davision A. Clinicopathological correlations and long-term follow-up of 253 United Kingdom patients with IgA nephropathy. A report from the MRC Glomerulonephritis Registry. QJM: An International Journal of Medicine 1992;84(1):619-27.

[18] Chacko B, John GT, Neelakantan N, Korula A, Balakrishnan N, Kirubakaran MG, et al. Presentation, prognosis and outcome of IgA nephropathy in Indian adults. Nephrology 2005;10(5):496-503.

[19] Ikee R, Kobayashi S, Saigusa T, Namikoshi T, Yamada M, Hemmi N, et al. Impact of hypertension and hypertensionrelated vascular lesions in IgA nephropathy. Hypertension research 2006;29(1):15.

[20] Frisch G, Lin J, Rosenstock J, Markowitz G, D'agati V, Radhakrishnan J, et al. Mycophenolate mofetil (MMF) vs placebo in patients with moderately advanced IgA nephropathy: a double-blind randomized controlled trial. Nephrology Dialysis Transplantation 2005;20(10):2139-45.

[21] Cattran DC, Appel GB. Treatment and prognosis of IgA nephropathy. Up to date.com; 2018.
[22] Fogo AB, Kashgarian M. Diagnostic Atlas of Renal Pathology E-Book. 3 rd ed. Philadelphia: Elsevier Health Sciences; 2017.

[23] Geddes CC, Rauta V, Gronhagen-Riska C, Bartosik LP, Jardine AG, Ibels LS, et al. A tricontinental view of IgA nephropathy. Nephrology Dialysis Transplantation 2003;18(8): 1541-8.

[24] Coppo R, D'Amico G. Factors predicting progression of IgA nephropathies. Journal of nephrology 2005;18(5):503-12.

[25] Goldblum JR, Lamps LW, McKenney JK, Myers JL. Rosai and Ackerman's Surgical Pathology E-Book. 11 nd ed. Philadelphia: Elsevier Health Sciences; 2018.

[26] Sahin OZ, Yavas H, Taslõ F, Gibyeli DG, Ersoy R, Uzum A, et al. Prognostic value of glomerular C4d staining in patients with IgA nephritis. International journal of clinical and experimental pathology 2014;7(6):3299.

[27] Floege J, van Roeyen C, Boor P, Ostendorf T. The role of PDGF-D in mesangioproliferative glomerulonephritis. IgA Nephropathy Today. Karger Publishers; 2007. p. 153-8.

[28] Terada Y, Yamada T, Nakashima O, Sasaki S, Nonoguchi $\mathrm{H}_{\text {, }}$ Tomita K, et al. Expression of PDGF and PDGF receptor mRNA in glomeruli in IgA nephropathy. Journal of the American Society of Nephrology 1997;8(5):817-9.

[29] Rath A, Tewari R, Mendonca S, Badwal S, Nijhawan VS. Oxford classification of IgA nephropathy and C4d deposition; correlation and its implication. Journal of nephropharmacology 2016;5(2):75.

[30] Baek HS, Hoon Han M, Jin Kim Y, Hyun Cho M. Clinical Relevance of C4d Deposition in Pediatric Immunoglobulin A Nephropathy. Fetal and pediatric pathology 2018;37(5): 326-36.

[31] Heybeli C, Unlu M, Yildiz S, Çavdar C, Sarioglu S, Camsari T. IgA nephropathy: association of $\mathrm{C} 4 \mathrm{~d}$ with clinical and histopathological findings and possible role of IgM. Renal failure 2015;37(9):1464-9.

[32] Nasri H, Ahmadi A, Rafieian-kopaei M, Bashardoust B, Nasri $\mathrm{P}$, Mubarak M. Association of glomerular C4d deposition with various demographic data in IgA nephropathy patients, a preliminary study. Journal of nephropathology 2015;4(1):19.

[33] Espinosa M, Ortega R, Sánchez M, Segarra A, Salcedo MT, González F, et al. Association of C4d deposition with clinical outcomes in IgA nephropathy. Clinical Journal of the American Society of Nephrology 2014;9(5):897-904.

[34] Maeng Y-I, Kim M-K, Park J-B, Cho C-H, Oh H-K, Sung WJ, et al. Glomerular and tubular C4d depositions in IgA nephropathy: relations with histopathology and with albuminuria. International journal of clinical and experimental pathology 2013;6(5):904.

[35] Pathogenesis of IgA nephropathy. In: Barratt J, Feehally J, Smith AC, editors. Seminars in nephrology. Elsevier; 2004.

[36] Drachenberg CB, Papadimitriou JC, Chandra P, Haririan A, Mendley S, Weir MR, et al. Epidemiology and Pathophysiology of Glomerular C4d Staining in Native Kidney Biopsies. Kidney International Reports 2019;4(11):1555-67.

[37] Miyake-Ogawa C, Miyazaki M, Abe K, Harada T, Ozono Y, Sakai $\mathrm{H}$, et al. Tissue-specific expression of renin-angiotensin system components in IgA nephropathy. American journal of nephrology 2005;25(1):1-12.

[38] Van Den Dobbelsteen ME, Van Der Woude FJ, Schroeijers WE, van den Wall AWL, van Es LA, Daha MR. Binding of dimeric and polymeric IgA to rat renal mesangial cells enhances the release of interleukin 6. Kidney international 1994;46(2):512-9.

[39] Horii Y, Iwano M, Hirata E, Shiiki H, Fujii Y, Dohi K, et al. Role of interleukin- 6 in the progression of mesangial proliferative glomerulonephritis. Kidney International Supplement 1993;(39). 